\title{
COMPARATIVE ANALYSIS OF ACTIVATED CORN COB AND BENTONITE CLAY FOR THE REMOVAL OF LEAD AND NICKEL FROM RAW WATER
}

\author{
Uchechi AKOMAH ${ }^{1}$; Ify Lawrence NWAOGAZIE², Onyewuchi AKARANTA ${ }^{3}$, Adekunle Olorunlowo DAVID ${ }^{4 *}$
}

\section{Abstract}

The extensive use of commercial activated carbon as an adsorbent for the purification of industrial effluent is not economical for small and medium-sized enterprises due to its high operational cost. This study was carried out to compare the adsorptive capacity of bentonite clay and activated corn cob ("BC" and "ACC") for the removal of lead (II) and nickel (II) ions from an aqueous solution. The results obtained from the characterization of the $B C$ and $\mathrm{ACC}$ are $\mathrm{pH}: 7.43$ and $6.74 ;$ moisture content: $36.45 \mathrm{~kg} / \mathrm{kg}$ and $12.10 \mathrm{~kg} / \mathrm{kg}$, and bulk density: $1.243 \mathrm{~g} / \mathrm{ml}$ and $1.162 \mathrm{~g} / \mathrm{ml}$, respectively. Normality tests using the coefficient of skewness indicated that the set of data was not normally distributed. An analysis of variance (ANOVA) test conducted using Friedman's 2-way ANO$V A$ test indicated $p$ values of 0.0253 against an alpha value of 0.05 , which indicates significance. The Friedman results indicated significance with respect to the varied dosages, initial concentrations, and contact time. The effect of the adsorbent was not significant. The adsorption isotherms were analysed using the Langmuir, Freundlich, and Temkin isotherms. Most research studies have shown that adsorption experiments performed using most low-cost materials tend to follow the Freundlich adsorption isotherm, but the results of this experimental study proved that activated corn cob and bentonite clay performed better with the Temkin adsorption isotherm with $0.879 \leq R^{2} \leq$ 0.917 for the bentonite clay and $0.9572 \leq R^{2} \leq 0.99$ for the activated corn cob respectively. The study revealed that these materials are good adsorbents that can be used for the removal of lead (II) and nickel (II) ions from an aqueous solution.

\section{Address}

1 World Bank Africa Centre of Excellence in Oilfields Chemicals Research, University of Port Harcourt, Choba, Rivers State, Nigeria.

2 Dept. of Civil and Environmental Engineering, University of Port Harcourt, Choba, Rivers State, Nigeria.

3 Dept. of Industrial Chemistry, University of Port Harcourt, Choba, Rivers State, Nigeria.

4 Dept. of Civil Engineering, Olabisi Onabanjo University, Ibogun campus, Ogun State, Nigeria.

* Corresponding author: adekunle.david@oouagoiwoye.edu.ng

Key words

- Adsorbent - bentonite clay \& activated corn cob,

- Adsorbates - lead and nickel,

- Langmuir,

- Freundlich and Temkin isotherms.

\section{INTRODUCTION}

Water is a fundamental need for human existence. Only about $0.0007 \%$ of the earth's fresh water is found in lakes, freshwater rivers, reservoirs, and groundwater resources (Anis Al-Layla et al., 1978; UN, 1997). Because of recent upsurges in the use of water, water scarcity has become a topical issue in Nigeria and the Sahelian coun- tries in Africa. The need to recycle wastewater is obvious in the northern part of Nigeria.

Ambali et al, (2015) stated that heavy metal pollution of the environment has become a growing ecological crisis and concern and is therefore the subject of much research. Various types of health issues in human beings are reported occurring due to water pollution. As far as inorganic and organic contaminants are concerned, the most signif- 
icant with regard to health are heavy metals, some of which include arsenic, lead, chromium, mercury, cadmium and nickel (WHO, 2010). Lead is one of the heavy metals of importance. Although lead is a naturally occurring substance, anthropogenic activities such as the burning of fossil fuels and mining have contributed to the discharge of high levels of lead in the environment. It is an important raw material for many products such as the production of lead-acid batteries and other metallic products. In Nigeria, most industries discharge their effluents into water bodies, particularly rivers and streams, and, as such, hazardous elements from the effluents contaminate the water (Nwaogazie and Ogelle, 1997; Nwaogazie, 1990). In humans, the kidney is most affected by lead (Abasi et al.,2011). One case of lead poisoning in recent times is the 2010 lead poisoning in the village of Bagega in Zamfara State in which 17,000 people were affected, and 500 casualties were recorded due to mining activities that led to the contamination of the domestic water source (WHO, 2010; Hassan et al., 2015)

Nickel and its compounds are used for much production in various industries. For instance, nickel is used for the production of stainless steel and is also used in the metallurgical, chemical and food processing industries. The consumption of nickel causes serious effects such as headaches, nausea, dry coughs, vomiting, chest pain, and a wide range of respiratory issues (Ambali et al., 2015).

The adsorption process is an efficient and effective method for the removal of a wide variety of toxic pollutants from raw water. Activated carbon has been globally recognized as the oldest, most widely used, and popular adsorbent in the water and wastewater treatment industries (Badmus et al., 2007). Conversely, due to the high cost of commercial activated carbon, research has been conducted on the use of more cost-effective adsorbents and lignocellulose wastes, such as corn cobs. The corn cob is the central core where kernels grow and is generally disposed of as waste. It is found in most parts of Nigeria, especially during the planting and harvesting seasons, which span from April to October. There is a vast deposit of bentonite clay in rivers in Nigeria spread across the country. Bentonite clay and corn cobs are both low-cost absorbents found in abundance in Nigeria. Therefore, the aim of this study is to establish the comparative effectiveness of their adsorption.

\section{MATERIALS AND METHODS}

\subsection{Collection and Preparation of the Samples}

The adsorbent samples used were corn cob and bentonite clay. The raw materials were washed with water from the tap to remove dirt and rinsed with de-ionized water; they were then sun dried for twenty-four (24) hours, after which they were crushed by a local pestle and mortar and then processed in a laboratory mill. The crushed samples were oven dried at $105^{\circ} \mathrm{C}$ for 12 hours.

Forty grams $(40 \mathrm{~g})$ of dried, ground, and sieved samples of corn cob were weighed into a two (2) litre beaker. Then, five hundred millilitres $(500 \mathrm{ml})$ of phosphoric acid $\left(\mathrm{H}_{3} \mathrm{PO}_{4}\right)$ were measured and added to the samples and left for 24 hours. The activated samples were washed with distilled water from the lab and the $\mathrm{pH}$ was adjusted to 6 . They were measured with a digital $\mathrm{pH}$ meter, and the samples were then dried in an oven at $105^{\circ} \mathrm{C}$. The raw bentonite clay was activated by thermal activation. The preparation of the thermally activated bentonite clay was carried out by calcinating the raw bentonite clay in a muffle furnace. The thermal activation of the bentonite clay was carried out with 30 grams of bentonite clay placed in a crucible. This given amount of bentonite clay was placed in a muffle furnace. Then the temperature of the muffle furnace was set at the preferred temperature of $105^{\circ} \mathrm{C}$ and allowed to rise to the expected temperature of $200^{\circ} \mathrm{C}$.

\subsection{Preparation of Lead and Nickel solutions}

The permissible limits set for lead $(\mathrm{Pb})$ and nickel (Ni) in water by the Nigerian Standard for Drinking Water Quality (NSDWQ) are $0.01 \mathrm{mg} / \mathrm{L}$ and $0.02 \mathrm{mg} / \mathrm{L}$ respectively. For this experiment stock solutions of both lead and nickel were produced in a laboratory.

One thousand milligrams per litre $(1000 \mathrm{mg} / \mathrm{l})$ of nickel acetate tetrahydrate $\left(\mathrm{CH}_{3} \mathrm{CO}_{2}\right)_{2}$ Ni. $\left.4 \mathrm{H}_{2} \mathrm{O}\right)$ (Source: BDH Chemicals U.K. with $\mathrm{Mw} .=248.86 \mathrm{~g}$. Grade: ANALAR (Analytical reagent)) were prepared for use throughout the experimental work by dissolving $4.235 \mathrm{~g}$ of nickel acetate tetrahydrate powder in $1000 \mathrm{ml}$ of distilled water. A stock solution of a single solute of $\mathrm{Pb}$ (II) was prepared by dissolving the requisite amount of lead nitrate in a $1000 \mathrm{ml}$ volumetric flask; de-ionised water was then added up to a mark to dilute it. The concentration of the single solute in the respective stock solution prepared was $1000 \mathrm{mg} / \mathrm{L}$. Test solutions having concentrations of 20 , $40,60,80$ and $100 \mathrm{mg} / \mathrm{L}$ were prepared for the experiment.

\subsection{Data Analysis}

The activated corn cob and bentonite clay produced were characterized by checking the size of the pores, $\mathrm{pH}$, moisture contents, bulk density and specific gravity. The nature of the interaction between the adsorbate and adsorbent can be expressed from the shape of the isotherm. The Langmuir, Freundlich and Temkin models were used to characterise the adsorbate adsorbent interaction in the experiment. A number of statistical data analyses methods were adopted, namely, a normality test using the coefficient of skewness and the Shapiro-Wilk test. The results of the normality test determine if parametric or non-parametric statistics will be adopted for the rest of the data analyses. The Analysis of Variance was featured to facilitate the comparative analysis of the efficiencies of the adsorbents (ACC and $\mathrm{BC}$ ) with respect to the removal of the $\mathrm{Pb}$ and $\mathrm{Ni}$ respectively. Linear regression modelling featured prominently in the data fitting.

\section{Langmuir Isotherm}

The Langmuir model can be presented by the equation:

$$
\frac{C_{e}}{q_{e}}=\frac{1}{q_{\max } k_{l}}+\frac{C_{e}}{q_{\max }}
$$

where: $\mathrm{q}_{\max }$ is the monolayer adsorption capacity of the adsorbent $(\mathrm{mg} / \mathrm{g}) ; \mathrm{k}_{1}$ is the Langmuir adsorption constant $(\mathrm{L} / \mathrm{mg}) ; \mathrm{C}_{\mathrm{e}}$ is the equilibrium metal ion concentration in the solution $(\mathrm{mg} / \mathrm{L})$; $\mathrm{q}_{\mathrm{e}}$ is the equilibrium metal ion concentration in the adsorbent $(\mathrm{mg} / \mathrm{g})$.

The values of $\mathrm{q}_{\max }$ and $\mathrm{k}_{\mathrm{L}}$ are calculated respectively from the slope and intercept of the plot of $\mathrm{C}_{\mathrm{e}} / \mathrm{q}_{\mathrm{e}} \mathrm{vs}$. $\mathrm{C}_{\mathrm{e}}$.

\section{Freundlich Isotherm}

The equations of the Freundlich adsorption models used in the study are expressed as:

$$
\log q_{e}=\log K_{f}+\frac{1}{n} \log C_{e}
$$

where: $\mathrm{K}_{\mathrm{F}}$ is a constant related to the adsorption capacity (Freundlich constant); $1 / \mathrm{n}$ is an empirical parameter related to the adsorption intensity (which varies with the heterogeneity of the material).

The values of $1 / \mathrm{n}$ and $\mathrm{K}_{\mathrm{F}}$ are calculated respectively from the slope and the intercept of the plot of $\log q_{e}$ vs. $\log C_{e}$.

\section{Temkin Isotherm}

This isotherm is composed of a factor that clearly takes into account the adsorbent-adsorbate interactions. The Temkin model is given by the following equation: 


$$
q_{e}=B \ln A_{T}+B \ln C_{e}
$$

where:

$$
B=\frac{R T}{b_{T}}
$$

$A_{T}=$ Temkin isotherm equilibrium binding constant $(\mathrm{L} / \mathrm{g}) ; b_{T}=$ Temkin isotherm constant; $R=$ universal gas constant $(8.314 \mathrm{~J} / \mathrm{mol} / \mathrm{K}) ;=$ Temperature at $298 \mathrm{~K} ; \mathrm{B}=$ Constant related to the heat of the sorption $(\mathrm{J} / \mathrm{mol})$.

\section{RESULTS AND DISCUSSION}

\subsection{Results}

\subsubsection{Characterization of the Adsorbents and Adsorption Experiments}

The characterization of the selected adsorbents in terms of their moisture content, porosity, $\mathrm{pH}$, bulk density and surface area was carried out (Table 1). The effect of the adsorbent dosage, contact time, and initial concentration on the removal of the $\mathrm{Pb}$ (II) and $\mathrm{Ni}$ (II) with the $\mathrm{ACC}$ and $\mathrm{BC}$ are represented in Figures 1, 2 and 3, respectively.

The surface area was calculated by the following equation:

$$
s=32 \mathrm{~V}-25
$$

where $s=$ surface area of the activated sample, and V= volume of sodium hydroxide required to raise the $\mathrm{pH}$ of the sample from 4 to 9

for ACC, $\mathrm{V}=7 \mathrm{ml}$. Substituting in Equation 5: $\mathrm{s}=32(7)-25=199 \mathrm{~m}^{2}$ for $\mathrm{BC}, \mathrm{V}=5 \mathrm{ml}$, which yields $135 \mathrm{~m}^{2}$

The bulk density is given by the following equation:

$$
\frac{\text { weight of dish }+ \text { sample }- \text { weight of dish }}{\text { weight of dish }+ \text { water }- \text { weight of dish }}
$$

while the porosity is given by the following equation:

$$
1-\frac{\text { Bulk density }}{\text { particle density }}
$$

Tab.1 PhysicoChemical Characteristics of Activated Corn Cob and Bentonite Clay

\begin{tabular}{|l|l|l|}
\hline Parameter (Unit) & $\begin{array}{l}\text { Activated Corn Cob } \\
\text { (ACC) }\end{array}$ & $\begin{array}{l}\text { Bentonite Clay } \\
\text { (BC ) }\end{array}$ \\
\hline $\mathbf{p H}$ & 6.74 & 7.43 \\
\hline Moisture Content, \% & 12.10 & 36.45 \\
\hline Bulk Density g/ml & 1.162 & 1.243 \\
\hline Porosity & 0.0077 & 0.0056 \\
\hline Surface Area $\mathbf{~ m}^{\mathbf{2}}$ & 199 & 135 \\
\hline
\end{tabular}

\subsubsection{Normality Test}

The laboratory results on the rates of adsorption were subjected to the normality test. The coefficient of skewness $(\alpha)$ was used to validate if the data sets were normally distributed for $\alpha=0$; otherwise, it is not normally distributed. The skewness approach was adopted, given that the data sets are of a small sample size. The results for the normality analysis are presented in Table 2 .

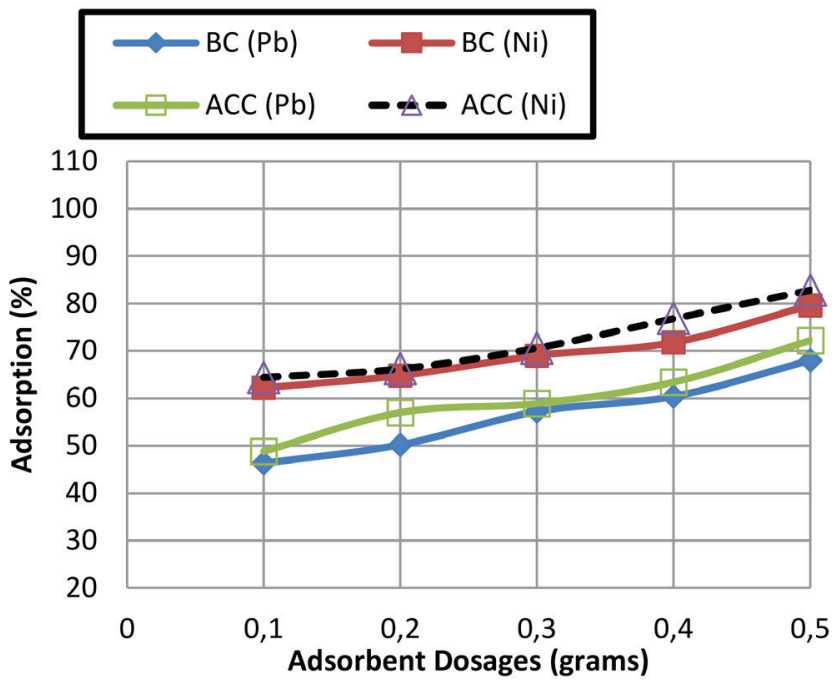

Fig. 1 Effect of adsorbent dosage on removal of adsorbate

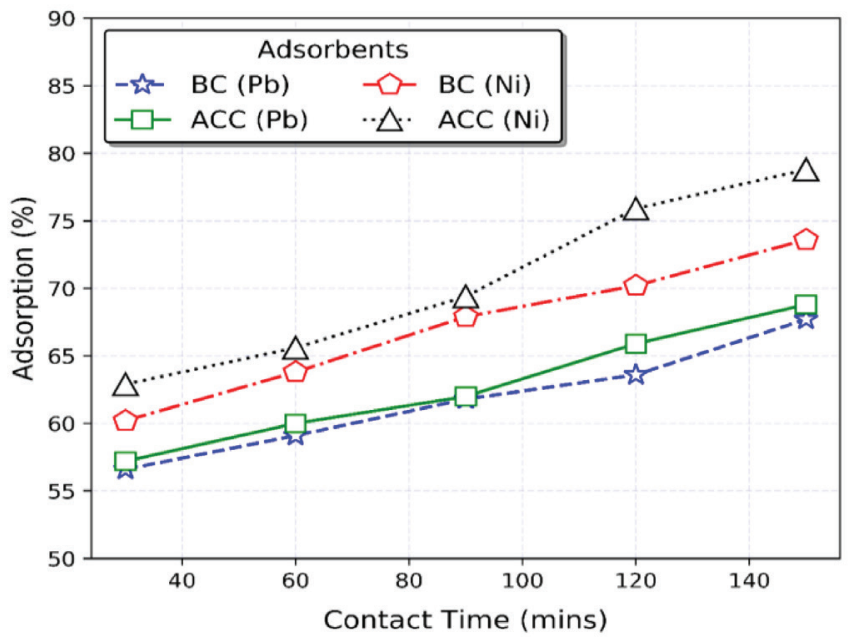

Fig. 2 Effect of contact time on removal of adsorbate

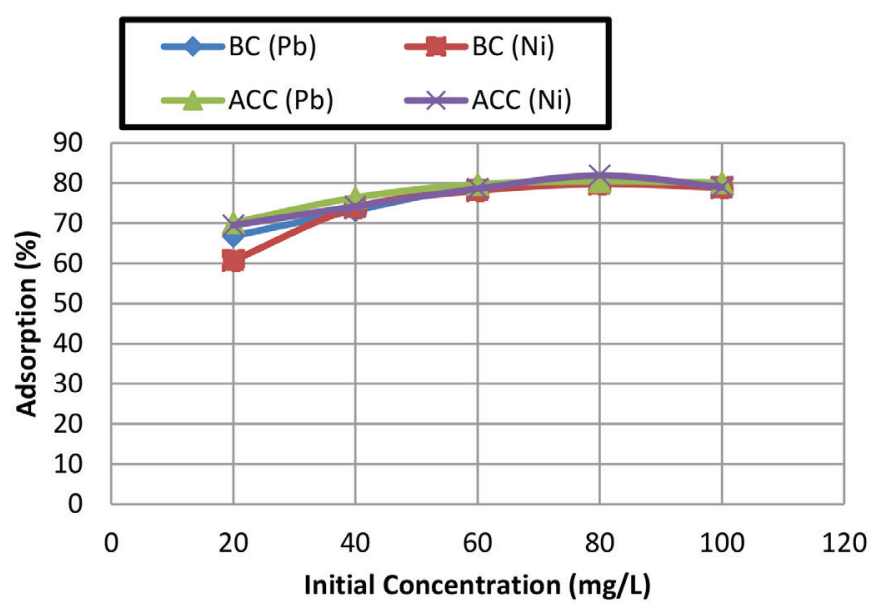

Fig. 3 Effect of initial concentration on removal of adsorbate 
Tab. 2 Normality Test for adsorption rates of $\mathrm{Pb}$ and Ni using ACC and $B C$

\begin{tabular}{|c|c|c|c|}
\hline Adsorption Test & Adsorbent & $\begin{array}{c}\text { Coefficient } \\
\text { of Skewness }\end{array}$ & Remark \\
\hline Adsorbent dosage (Pb) & BC & 0.2271 & NND $^{+}$ \\
\hline & ACC & 0.2725 & NND \\
\hline Adsorbent dosage (Ni) & BC & 0.7551 & NND \\
\hline & ACC & 0.5829 & NND \\
\hline Contact Time (Pb) & BC & 0.325 & NND \\
\hline & ACC & 0.223 & NND \\
\hline Contact Time(Ni) & BC & -0.208 & NND \\
\hline & ACC & 0.220 & NND \\
\hline Initial Conc $(\mathbf{P b})$ & BC & 0.678 & NND \\
\hline & ACC & 0.585 & NND \\
\hline Initial Conc $(\mathbf{N i})$ & BC & 1.351 & NND \\
\hline & ACC & 1.088 & NND \\
\hline
\end{tabular}

Level of significance $=0.05 ;{ }^{+} \mathrm{NND}=$ Not Normally Distributed

Given that the experimental data indicates "not normally distributed", further statistical analyses on the data sets followed non- parametric methods.

\subsubsection{Analysis of Variance (ANOVA)}

The Mann-Whitney and Friedman two-way ANOVA tests, which are non-parametric, were carried out on the data sets. First, the Mann-Whitney test was performed for the two adsorbents (ACC and $\mathrm{BC})$ with respect to the adsorption rates, dosage, contact time and varied initial concentration, which indicate "not-significant" in six (6) cases.

Second, the Friedman two-way ANOVA test was conducted for the six (6) mentioned cases, and the summary results are as shown in Table 3.

\subsubsection{Adsorbate- Adsorbent Modelling}

The adsorbate-adsorbent concentrations were represented using the Langmuir, Freundlich, and Temkin isotherm models. For the Langmuir isotherm, Figures 4 to 7 show the extent of the adsorption of the lead and nickel and the concentration of adsorbate. The models developed relate the extent of adsorption of the lead and nickel, and the concentration of the adsorbate using the Freundlich adsorption Isotherm are presented in Figures 8 to 11. For the Temkin Adsorption isotherm the models developed relating to the extent of the adsorption of the lead and nickel and the concentration of adsorbate are presented in Figures 12 to 15.

Tab. 3. Friedman two-way test for the adsorption rates of $\mathrm{Pb}$ and Ni using $A C C$ and $B C$

\begin{tabular}{|c|c|c|c|c|c|}
\hline Adsorption Test & Q (Observed value) & Q (Critical value) & DF & p-value & Alpha value \\
\hline Adsorbent dosage (Pb) & 5 & 3.8415 & 1 & 0.0253 & 0.05 \\
\hline Adsorbent dosage (Ni) & 5 & 3.8415 & 1 & 0.0253 & 0.05 \\
\hline Contact Time (Pb) & 5 & 3.8415 & 1 & 0.0253 & 0.05 \\
\hline Contact Time(Ni) & 5 & 3.8415 & 1 & 0.0253 & 0.05 \\
\hline Initial Conc (Pb) & 5 & 3.8415 & 1 & 0.0253 & 0.05 \\
\hline Initial Conc $(\mathbf{N i )}$ & 5 & 3.8415 & 1 & 0.0253 & 0.05 \\
\hline
\end{tabular}

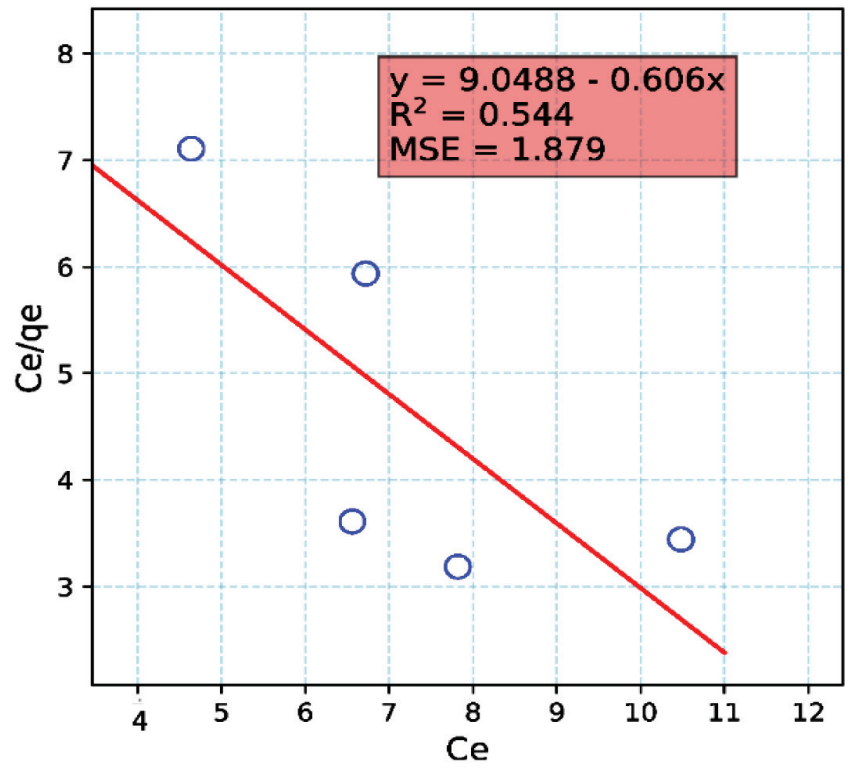

Fig. 4 Ce versus Celqe for $B C$ adsorbent $P b$ adsorption (Langmuir model)

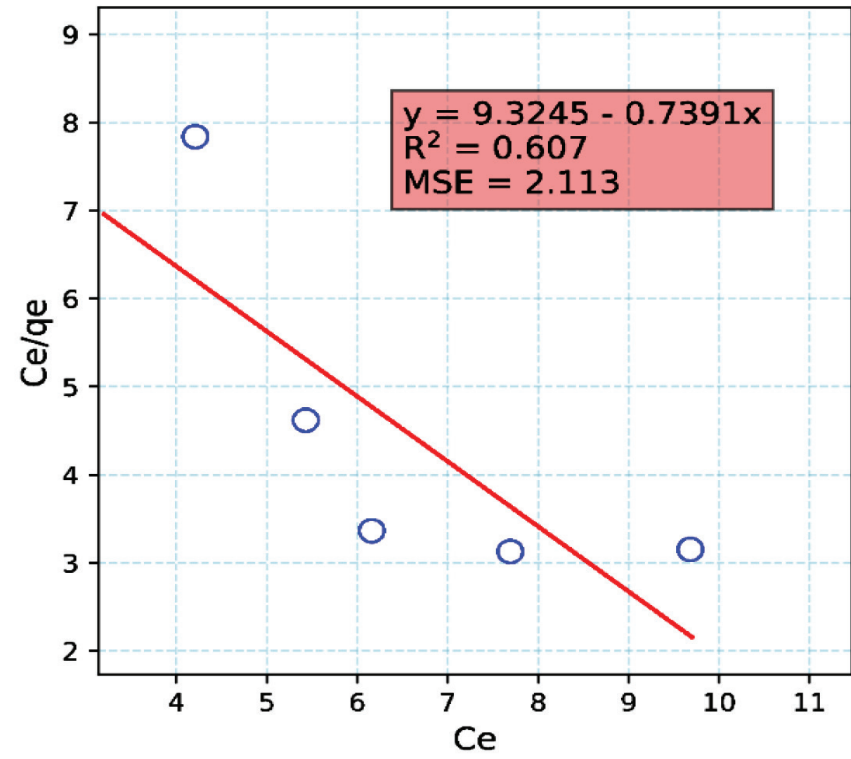

Fig. 5 Ce versus Celqe for ACC adsorbent Pb adsorption (Langmuir model) 


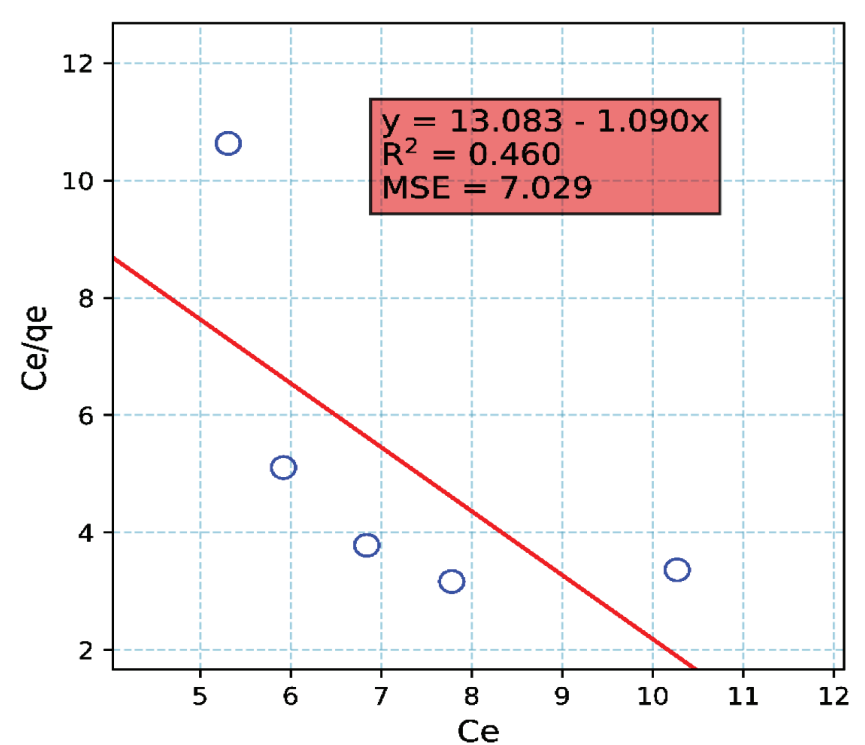

Fig. 6 Ce versus Celqe for BC adsorbent for Ni adsorption (Langmuir)

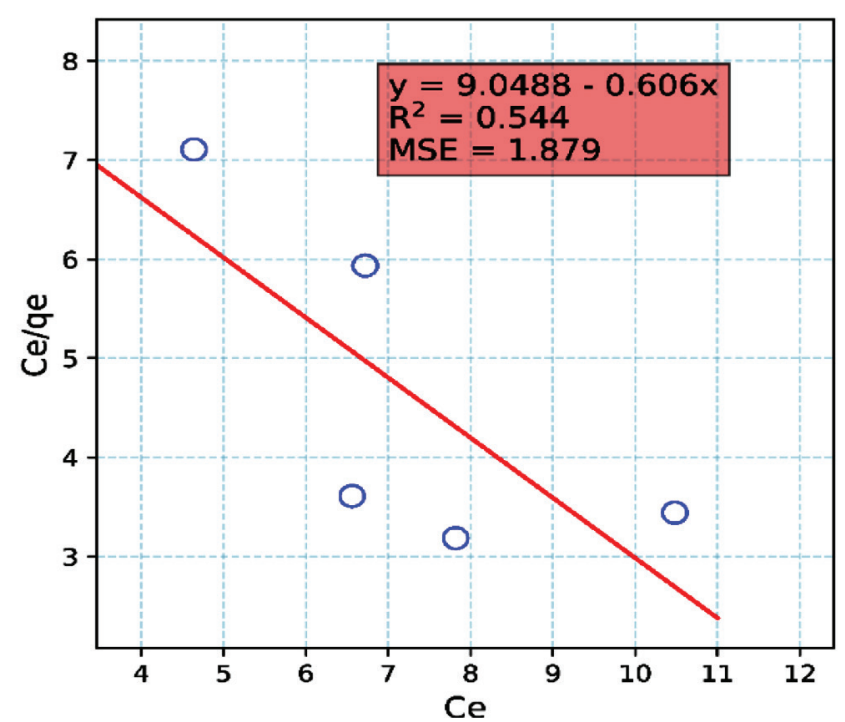

Fig. 8 log qe versus $\log C$ e for $B C$ adsorbent for $P b$ adsorption (Freundlick)

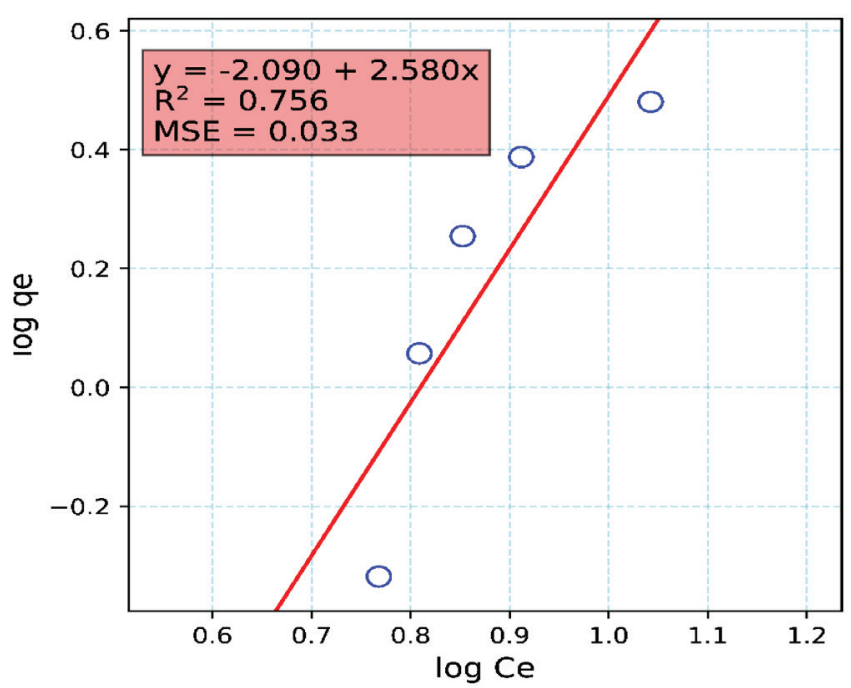

Fig. $10 \log$ qe versus $\log$ Ce for BC adsorbent for Ni adsorption (Freundlick)

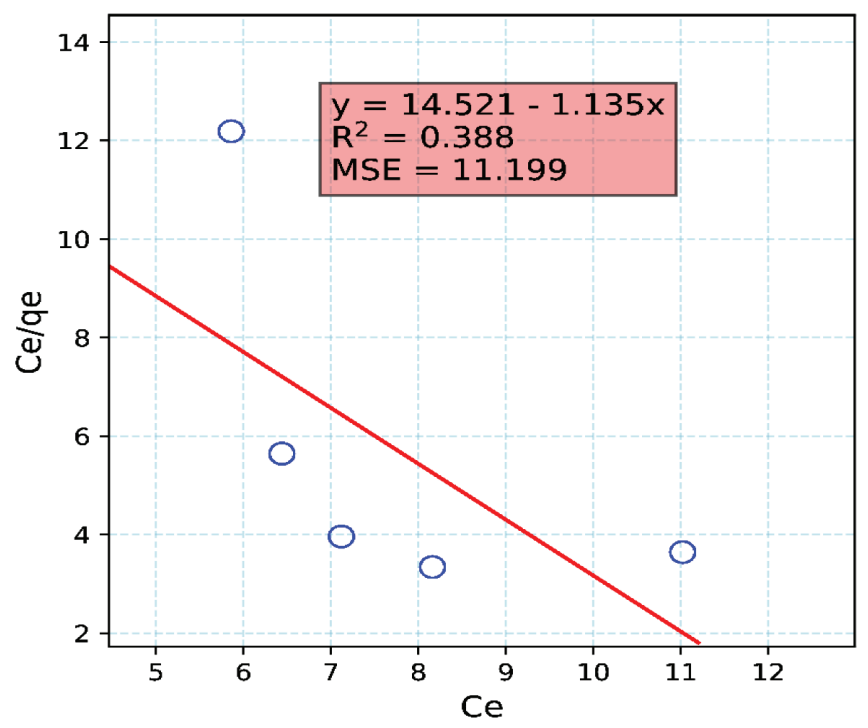

Fig. 7 Ce versus Ce/qe for ACC adsorbent for Ni adsorption (Langmuir)

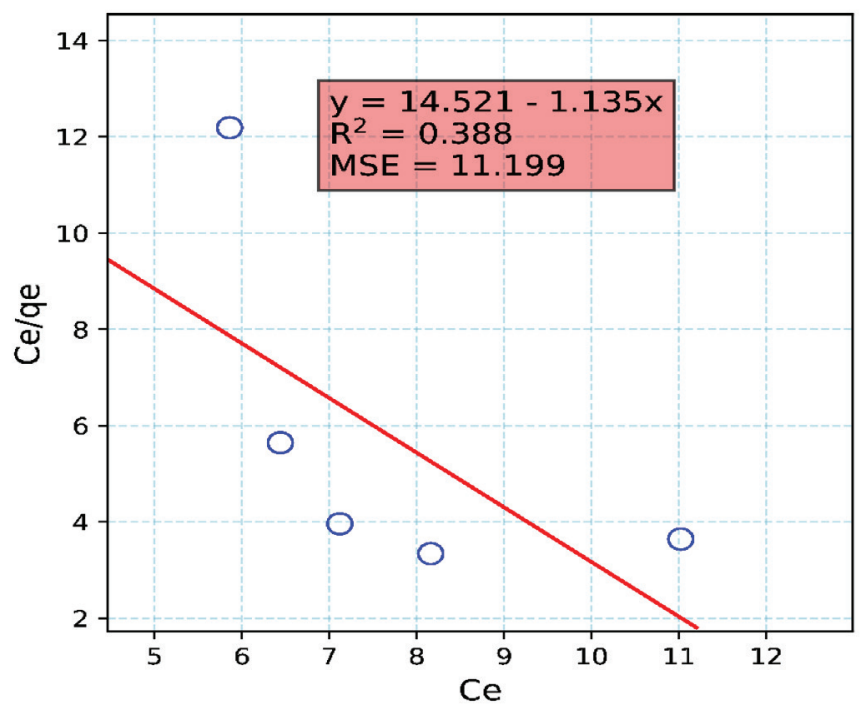

Fig. $9 \log$ qe versus $\log C$ e for ACC adsorbent for Pb adsorption (Freundlick)

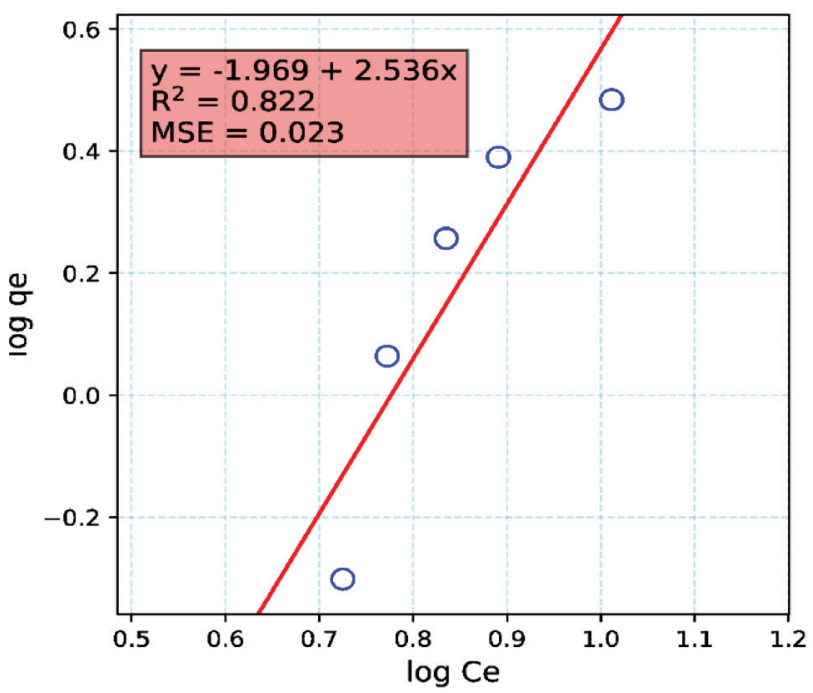

Fig. $11 \log$ qe versus $\log$ Ce for ACC adsorbent for Ni adsorption (Freundlick) 


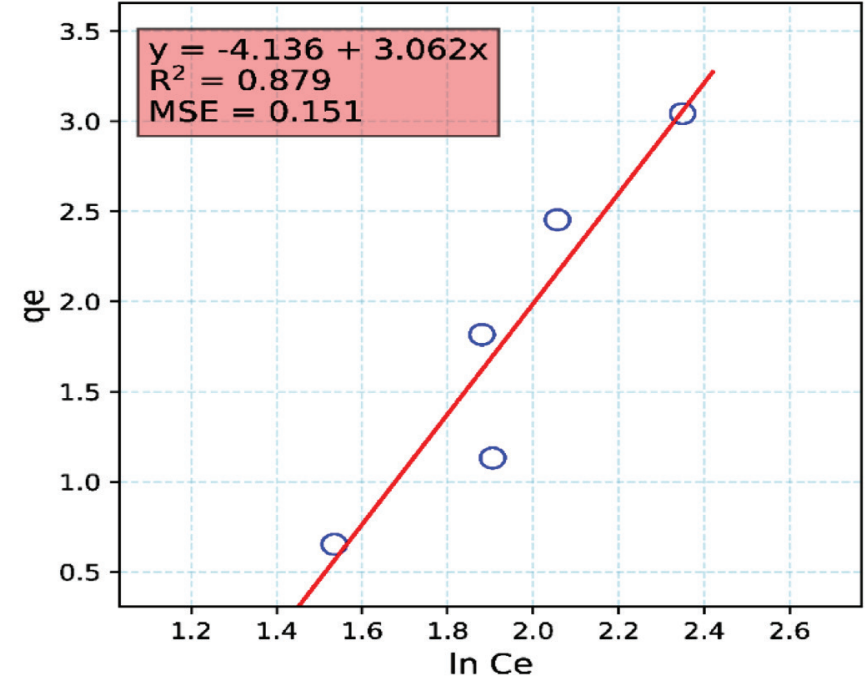

Fig. 12 qe versus ln Ce for $B C$ adsorbent for $\mathrm{Pb}$ adsorption (Temkin's model)

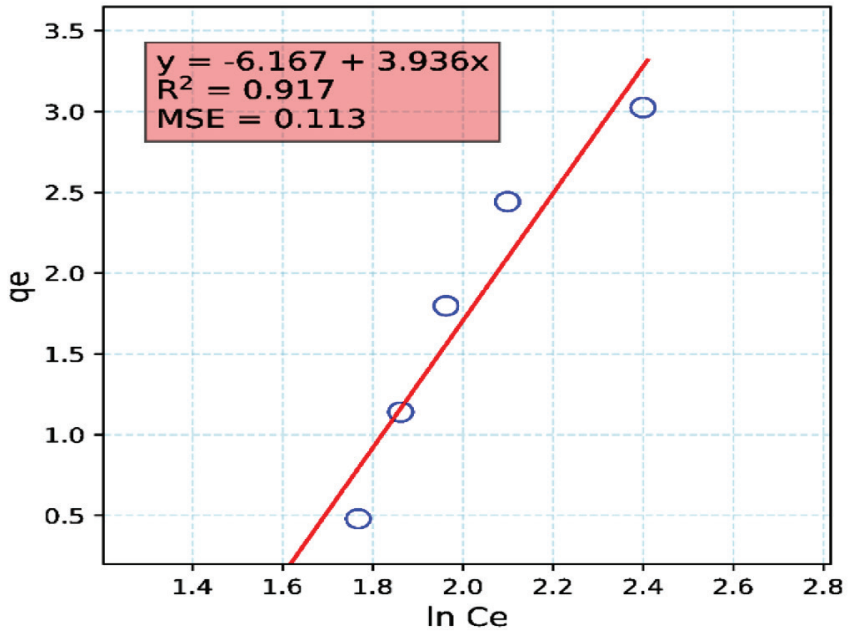

Fig. 14 qe versus ln Ce for BC adsorbent for Ni adsorption (Temkin)

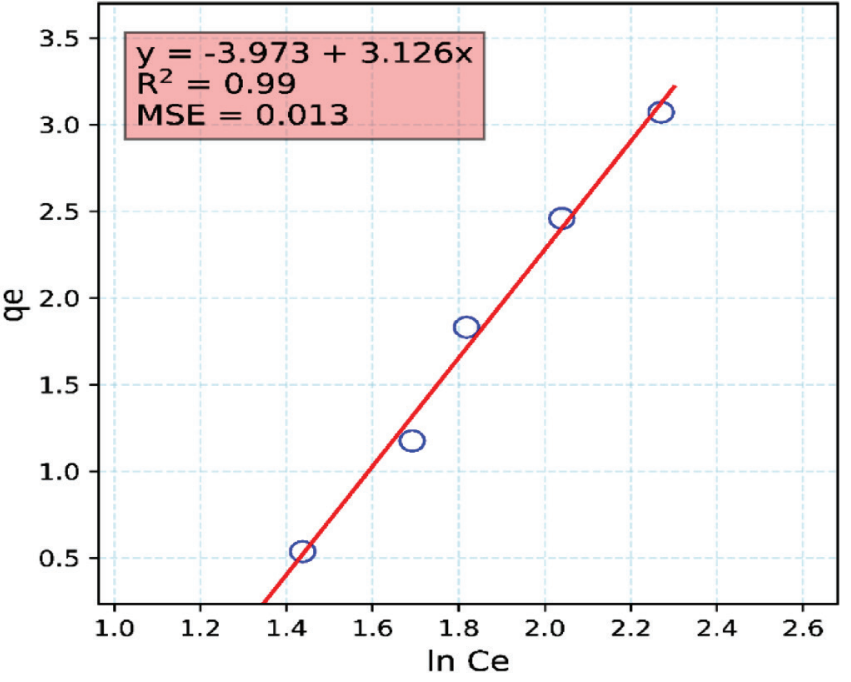

Fig. 13 qe versus ln Ce for $A C C$ adsorbent for $\mathrm{Pb}$ adsorption (Temkin)

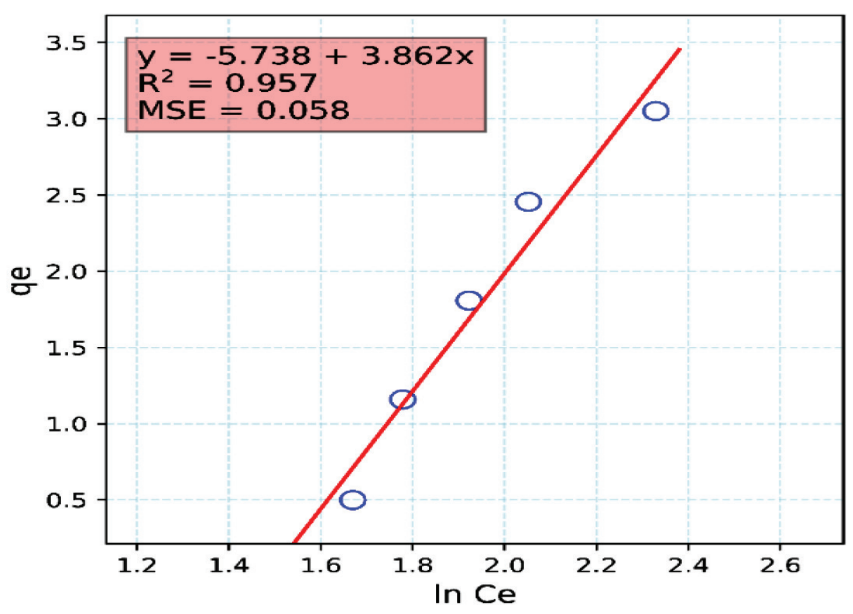

Fig. 15 qe versus ln Ce for ACC adsorbent for Ni adsorption (Temkin)

Tab. 4 Summary of the Model Constants of the Adsorption Isotherms

\begin{tabular}{|c|c|c|c|c|}
\hline \multirow{2}{*}{ Adsorbents } & \multirow{2}{*}{ Adsorbate } & \multicolumn{3}{|c|}{ Adsorption Isotherm Models } \\
\hline & & Langmuir & Freundlich & Temkin \\
\hline \multirow{2}{*}{$\mathrm{BC}$} & $\mathrm{Pb}$ (II) ion & $\begin{array}{c}q_{O}=-1.650 \\
\mathrm{k}=-0.067 \\
\mathrm{R}^{2}=0.544 \\
\mathrm{MSE}=1.879\end{array}$ & $\begin{array}{c}\mathrm{k}_{\mathrm{f}}=0.036 \\
\mathrm{n}=0.509 \\
\mathrm{R}^{2}=0.864 \\
\mathrm{MSE}=0.013\end{array}$ & $\begin{array}{c}\mathrm{B}_{1}=3.126 \\
\mathrm{k}_{\mathrm{T}}=0.281 \\
\mathrm{R}^{2}=0.99 \\
\mathrm{MSE}=0.013\end{array}$ \\
\hline & $\mathrm{Ni}$ (II) ion & $\begin{array}{c}q_{O}=-1.353 \\
\mathrm{k}=-0.079 \\
\mathrm{R}^{2}=0.607 \\
\mathrm{MSE}=2.113\end{array}$ & $\begin{array}{c}\mathrm{k}_{\mathrm{f}}=0.033 \\
\mathrm{n}=0.481 \\
\mathrm{R}^{2}=0.928 \\
\mathrm{MSE}=0.0087\end{array}$ & $\begin{aligned} \mathrm{B}_{1} & =3.062 \\
\mathrm{k}_{\mathrm{T}} & =0.259 \\
\mathrm{R}^{2} & =0.879 \\
\mathrm{MSE} & =0.151\end{aligned}$ \\
\hline \multirow{2}{*}{$\mathrm{ACC}$} & $\mathrm{Pb}$ (II) ion & $\begin{array}{c}q_{O}=-0.881 \\
\mathrm{k}=-0.078 \\
\mathrm{R}^{2}=0.388 \\
\mathrm{MSE}=11.199\end{array}$ & $\begin{array}{c}\mathrm{k}_{\mathrm{f}}=0.008 \\
\mathrm{n}=0.288 \\
\mathrm{R}^{2}=0.756 \\
\mathrm{MSE}=0.033\end{array}$ & $\begin{aligned} \mathrm{B}_{1} & =3.862 \\
\mathrm{k}_{\mathrm{T}} & =0.226 \\
\mathrm{R}^{2} & =0.957 \\
\mathrm{MSE} & =0.058\end{aligned}$ \\
\hline & $\mathrm{Ni}$ (II) ion & $\begin{array}{c}q_{O}=-0.917 \\
\mathrm{k}=-0.083 \\
\mathrm{R}^{2}=0.460 \\
\mathrm{MSE}=7.029\end{array}$ & $\begin{array}{c}\mathrm{k}_{\mathrm{f}}=0.011 \\
\mathrm{n}=0.394 \\
\mathrm{R}^{2}=0.822 \\
\mathrm{MSE}=0.023\end{array}$ & $\begin{aligned} \mathrm{B}_{1} & =3.936 \\
\mathrm{k}_{\mathrm{T}} & =0.209 \\
\mathrm{R}^{2} & =0.917 \\
\mathrm{MSE} & =0.113\end{aligned}$ \\
\hline
\end{tabular}


A summary tableau of the isotherm models used for the data fitting with their respective calibrated constants is as shown in Table 4.

The graphic abstract is presented in Figure 16.
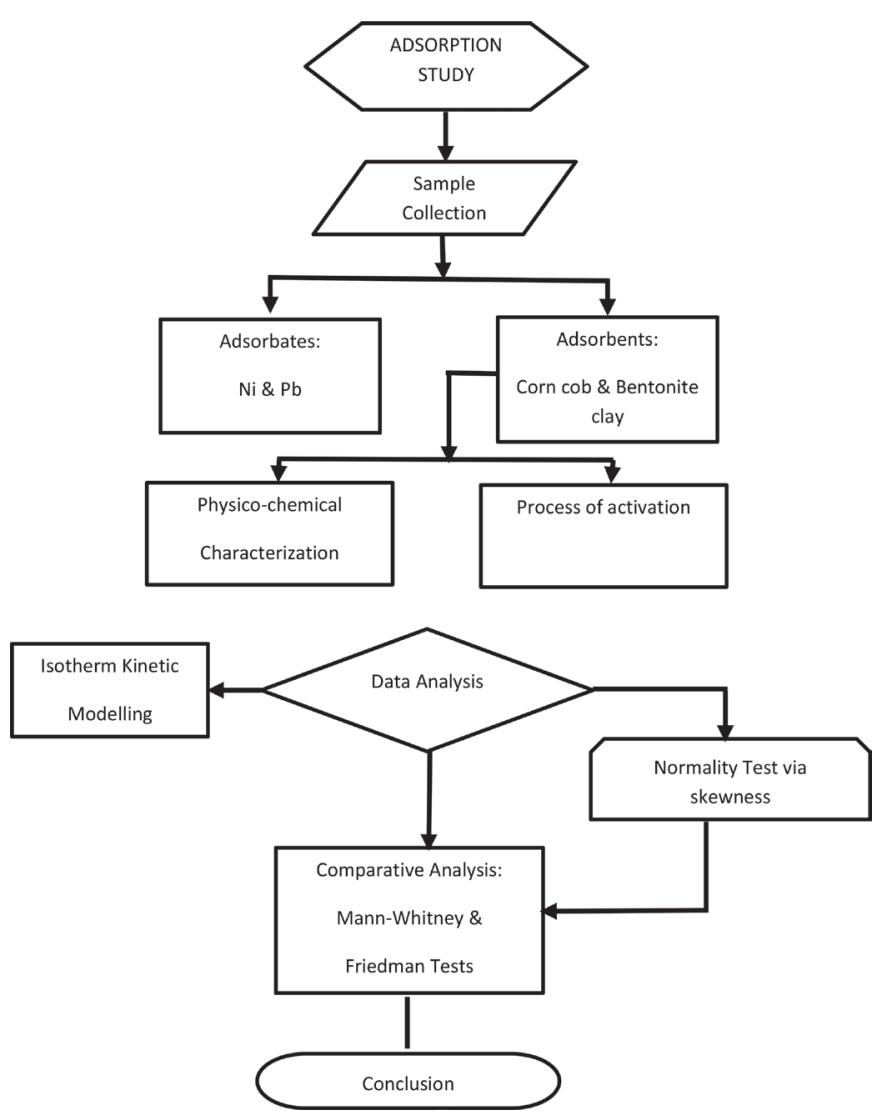

Fig. 16 Graphic abstract for the process

\subsection{Discussion}

\subsubsection{Characterization of the Adsorbents and Adsorption experiments}

From Table 1 it can be seen that while the $\mathrm{BC}$ had a higher moisture content of $36.45 \%$ versus $12.10 \%$ for the ACC (Nwosu et al.,2018), the ACC presented a higher surface area of $199 \mathrm{~m}^{2}$ versus the $135 \mathrm{~m}^{2}$ presented by BC. Figure 1 showed that as the adsorbent dosage increased, the percentage of $\mathrm{Pb}$ (II) and $\mathrm{Ni}$ (II) ions removed also increased for both the $\mathrm{BC}$ and $\mathrm{ACC}$ adsorbents. This observation is in agreement with that of Bartczak et al. (2015). Figure 2 shows that as the contact time increased, so did the percentage of $\mathrm{Pb}$ (II) and $\mathrm{Ni}$ (II) removal. It also indicated a strong linear relationship between the contact time and percentage of the adsorption of the $\mathrm{Pb}$ (II) and $\mathrm{Ni}$ (II) ions. Figure 3 shows that as the initial concentration increased, so did the percentage removal of the $\mathrm{Pb}$ (II) and $\mathrm{Ni}$ (II). The same effect was observed by Marshell and Champagne (1995).

\subsubsection{Normality Test}

Normality tests using the coefficient of skewness were carried out on the data sets to determine if the data sets were normally distributed. Most normality tests have little power to reject the null hypothesis, which states that the samples are from a normally distributed population when the sample size is relatively small (Oztuna et al., 2006). Table 2 shows that the coefficients of skewness of the ACC and $\mathrm{BC}$ were not zero, thereby indicating that the data sets are not symmetrical. They are therefore not normally distributed.

\subsubsection{Analysis of Variance}

The six (6) repeated tests (Table 3) according to Mann-Whitney indicated "non-significant" as computed p values ranged from 0.5309
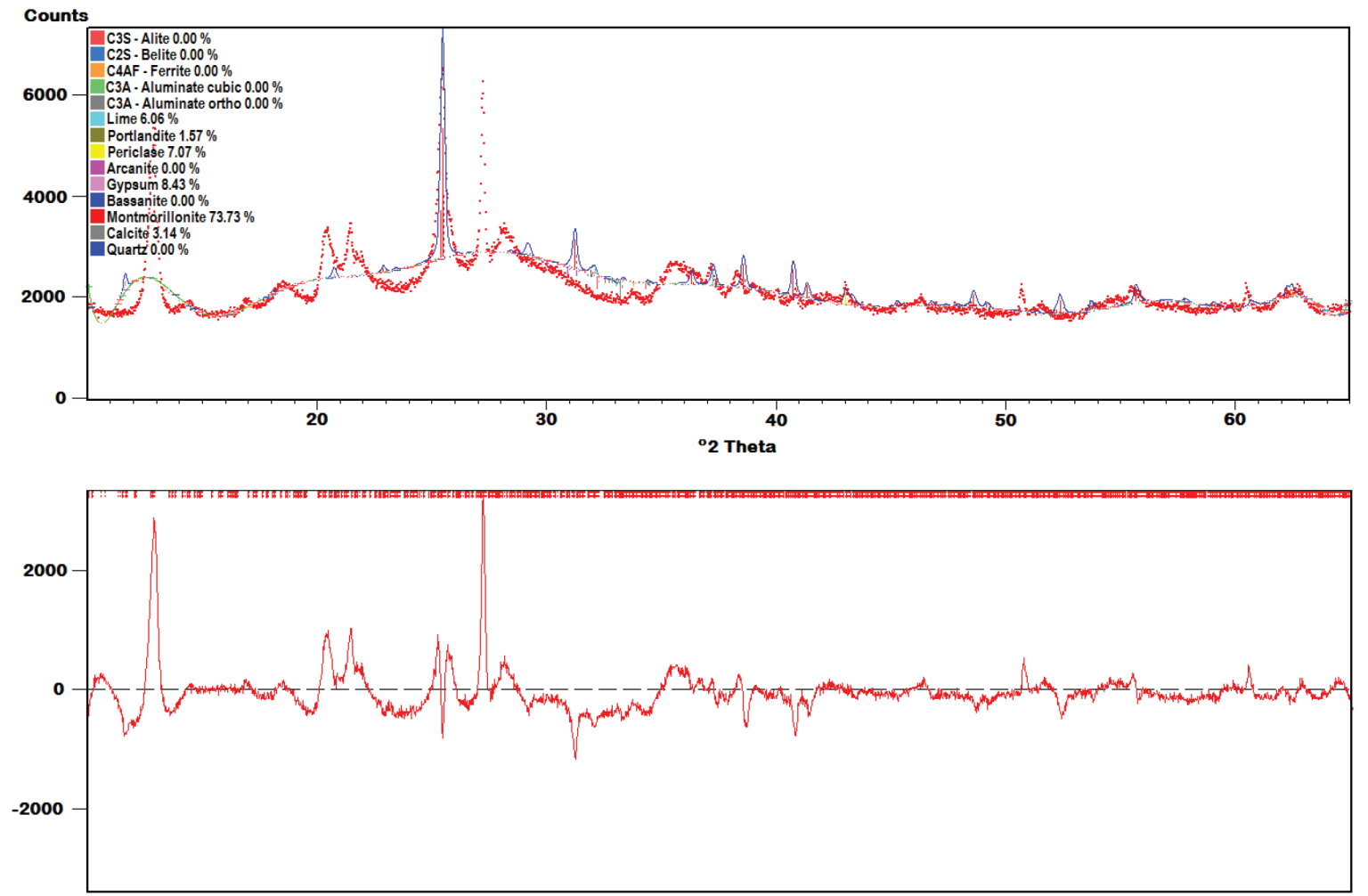

Fig. $17 X$-ray diffraction spectrum of the bentonite (Opafola, et al. 2021) 
to 0.6761 against an alpha value of 0.05 . However, the Friedman two - way Anova test for the six (6) cases (Table 3) recorded p values of 0.0253 against the alpha value of 0.05 , which indicates "significance". Comparatively, as per the Mann-Whitney test for which the input data sets do not include the dosage, the Friedman results indicate "significance" with respect to the varied dosages, initial concentrations, and contact time. The effect of the adsorbent is not significant.

\subsubsection{Modelling the Adsorbate Adsorbent}

The linear models developed were compared with the Langmuir adsorption model, and the constant terms of the Langmuir adsorption model were obtained by directly comparing the two equations for each of the graphs. Figures 4 and 5 indicate that the coefficients of determination of the model developed were 0.544 and 0.607 , while the mean squared errors were 1.879 and 2.113 , respectively, for the lead adsorption, while Figures 6 and 7 show the coefficients of determination as 0.388 and 0.46 with the mean squared errors as 11.199 and 7.029, respectively, for the nickel adsorption.

Figures 8 and 9 show that the coefficients of determination of the model developed (the Freundlick isotherm model) were 0.864 and 0.928 , while the mean squared errors were 0.013 and 0.0087 , respectively, for the lead adsorption. Figures 10 and 11 indicate the coefficients of determination as 0.756 and 0.822 with the mean squared errors as 0.033 and 0.023 , respectively, for the nickel adsorption.

Figures 12 and 13 show the coefficients of determination of the Temkin model developed were 0.99 and 0.879 , while the mean squared errors were 0.013 and 0.151 , respectively, for the lead adsorption. Figures 14 and 15 indicate the coefficients of determination were 0.957 and 0.917 with mean squared errors as 0.058 and 0.113 , respectively, for the nickel adsorption.

The results in Table 5 detailing the coefficient of determination of the isotherms used show that the Temkin isotherm model best described the adsorption of both adsorbates (Demir et al., 2019).

\subsubsection{X-ray microanalysis}

The X-ray microanalysis for the bentonite clay is shown in Figure 17. The results revealed that the dominant mineral in bentonite is montmorillonite with a $72.73 \mathrm{wt} \%$.

\section{CONCLUSION}

The present study shows that chemically-treated corn cob and thermally-activated bentonite clay are effective adsorbents for the removal of lead and nickel ions from aqueous solutions. The adsorption process is a function of the adsorbent and adsorbent concentrations, dosages, and time. The equilibrium adsorption data are satisfactorily fitted in the empirical models of Langmuir $<$ Freundlich $<$ Temkin, in the case of both the lead and nickel ions. Both adsorbents were found to be very effective in the removal of heavy metals from raw water with about $82 \%$ removal achieved. The economic feasibility of these low - cost adsorbents over commercially- activated carbon (CAC) is another important aspect of the present study. It was found that both corn cobs and bentonite clay are abundant locally and are much cheaper than CAC. The results are not only important for the local industries, but also for developing nations due to the resultant social and environmental benefits (they keep the environment clean from corn cob litter, etc.). 


\section{REFERENCES}

Adil, M. (2006) Preparation, modification and characterization of activated carbons for batch adsorption studies on the removal of selected metal ions. M.Sc Thesis, University of Technology, Malaysia

Agunwamba, J. C. (2001) Waste Engineering and Management Tools. In J.C. Agunwamba, Principle of Wastewater Treatment (37). Enugu: Imaculate Publication, Ltd.

Ambali A.B. - Evbuomwan B. O. - Momoh Y. (2015) Comparative Study on the Adsorption Capacity of Snail And Perewinkle Shells for the Removal of Nickel(Ii) Ion from Aqueous Solution. International Journal of Geology, Agriculture and Environmental Sciences 3(1):39-50

Ambali, A.B. - Evbuomwan, B.O. - Momoh, Y. (2015) Comparative study on the adsorbtion capacity of snail and periwinkle shells for the removal of nickel ion from aqueous solution. International Journal of Geology, Agriculture and Environmental Science $3(1): 18-26$

Al-Layla, M. A. - Ahmad, S. - Middlebrooks, J. E. (1978) Water Supply Engineering Design, Ann Arbor Science, Publishers Inc. Michigan, pp. 16-25, 55-57,133-143.

Arceivala, S.J. - Asolekar, S. R. (2011) Waste Water Treatment for Pollution Control and Reuse. New Delhi: Teta McGraw-Hill.

Ayyappan, R. - Carmalin-Sophia, A. - Swaminathan, K. - Sandhya, S. (2005) Removal of Pb (II) from aqueous solution using carbon derived from agricultural wastes, Process Biochemistry, 40, 1293-1299.

Azab, M. S. (2008) Waste Water Treatment Technology and Environmental Management Using Sawdust Bio-Mixture, Journal of Tabah University for Science. 1 (1): 12-23.

Badmus, M. A. O - Audu, T. O. K. - Anyata, B. U. (2007a) Removal of copper from industrial wastewaters by activated carbon prepared from periwinkle shells. Korean Journal of Chemical Engineering. $24,246-252$

Badmus, M. A. O - Audu, T. O. K. - Anyata, B.U. (2007b) Removal of lead ion from industrial waste waters by activated carbon prepared from periwinkle shells (Typanotonus fuscatus). Turkish Journal of Engineering Environmental Science, 31, 251-263.

Bartczak P. - Norman, M. - Klapiszewski, Ł. - Karwańska, N. Kawalec, M. - Baczyńska, M - Wysokowski, M. - Zdarta, J. - Filip Ciesielczyk, F. - Jesionowski, T (2015) Removal of nickel(II) and lead(II) ions from aqueous solution using peat as a lowcost adsorbent: A kinetic and equilibrium study. Arabian Journal of Chemistry, 11(8), 1209-1222

Demir F. - Ömer L. - Burak B. (2019) Determined of Equilibrium Adsorption Isotherm Model Pertechnetate Oxoanion Onto Activated Carbon. Sinop Uni J Nat Sci 4 (1): 37-46
Hassan, M. - Abdulmumin, A. - Sallau, M. S. - Hussaini, M.- Mohammed, A. K. (2015) Zamfara lead poisoning saga: Comparison of lead contamination level of water samples and lead poisoning in Bagega Artisanal gold mining district, Nigeria. Journal of Chemical and Pharmaceutical Research (73):7-12

Marshell, W. E. - Champagne, E. T. (1995) Agricultural by products as adsorbents for metal ions in laboratory solutions and in manufacturing wastewater, Journal of Environmental Science and Health, A30, 241

Nwaogazie, I. L. - Ogelle, E. (1997) Water Quality Modelling of Rice-irrigated Obinna River Basin,Uzo-Uwani. Journal of Water, Air and Soil Pollution.Vol.100, pp. 197-212.

Nwaogazie, I. L. (1990) Pollution Modelling: A necessity for provision of water for all in Nigeria. Nigerian Journal of Technology, Vol. 2, pp. 49-55.

Nwosu F. O. - Oluwaseun J. A. - Rukayat M. O. - Bukola, G. R. (2018) Preparation and characterization of adsorbents derived from bentonite and kaolin clays, Applied Water Science 8:195

Oztuna D. - Elhan, A. - Tuccar, E. (2006) Investigation of four different normality tests in terms of type 1 error rate and power under different distributions, Turkish Journal of Medical Sciences 36(3):171-176.

UN (1997) Comprehensive assessment of the fresh water resources of the world. Report of the Secretary General, United Nations Economic and Social Council (1997), Commission on Sustainable Development, $5^{\text {th }}$ ed. pp. 19-25.

WHO (1984) Health criteria and other supporting information, vol. 101: 2. World Health Organisation.

WHO (2010) Environmental Health Criteria (EHC) on inorganic lead. Disease outbreak report on lead poisoning in Nigeria. Vol. 2: World Health Organisation.

WHO (2004) Guidelines for drinking water quality. Vol. 2. Geneva: World Health Organisation.

Yildiz, N. - Gonulsen, R. - Koyuncu, H. - Calimili, A. (2005) Adsorption of benzoic acid and hydroquinone by organically modified bentonite clay. Colloids Surf. A: Physicochem Eng. Asp. 260, 87-94.

Opafola, O. T. - David, A. O. - Ajibade, F. O. - Adeyemi, H. O. Solana, O. I. - Odugbose, B. D. (2021) The utilization of bentonite enhanced termite mound soil mixture as filter for the treatment of paint industrial effluent. SN Applied Sciences. 3, 415. https :// doi.org/10.1007/s42452-021-04405-x. 